\title{
Adding Gabapentin to a multimodal regimen does not reduce acute pain, opioid consumption or chronic pain after total hip arthroplasty
}

\author{
H. Clarke ${ }^{1,2,3}$, S. Pereira ${ }^{2}$, D. Kennedy ${ }^{2}$, J. Andrion ${ }^{2}$, N. Mitsakakis ${ }^{1}$, J. Gollish ${ }^{2}$, J. Katz ${ }^{1,2,4}$ and J. Kay ${ }^{2,3}$ \\ ${ }^{1}$ Department of Anesthesia and Pain Management, Toronto General Hospital, Toronto, ON, ${ }^{2}$ Holland Orthopedic and Arthritic Centre, \\ Sunnybrook Health Sciences Centre, Toronto, ON, ${ }^{3}$ Department of Anesthesia, University of Toronto, Toronto, ON and ${ }^{4}$ Department of \\ Psychology and School of Kinesiology and Health Science, York University, Toronto, ON
}

\begin{abstract}
Background: Gabapentin (GPN) is effective in reducing post-operative pain and opioid consumption, but its effects with regional anesthesia for total hip arthroplasty (THA) are not known. We designed this study to determine whether (1) gabapentin administration reduces pain and opioid use after THA using a multimodal analgesic regimen including spinal anesthesia; (2) pre-operative administration of gabapentin is more effective than postoperative administration.

Methods: After REB approval and informed consent, 126 patients were enrolled in a double-blinded, randomizedcontrolled study. Patients received acetaminophen $1 \mathrm{~g}$ per os (p.o.), celecoxib $400 \mathrm{mg}$ p.o. and dexamethasone $8 \mathrm{mg}$ intravenously, $1-2 \mathrm{~h}$ pre-operatively. Patients were randomly assigned to one of three treatment groups (G1: Placebo/Placebo; G2: GPN/Placebo; G3: Placebo/GPN). Patients received gabapentin $600 \mathrm{mg}$ (G2) or placebo (G1 and G3) $2 \mathrm{~h}$ before surgery. All patients had spinal anesthesia [ $15 \mathrm{mg}$ (3cc) of $0.5 \%$ hypobaric bupivacaine with $10 \mu \mathrm{g}$ of fentanyl]. In the post-anesthetic care unit, patients received gabapentin $600 \mathrm{mg}$ (G3) or placebo (G1 and G2). On the ward, patients received acetaminophen $1000 \mathrm{mg}$ p.o. q6h, celecoxib $200 \mathrm{mg}$ p.o. q12h and a morphine PCA
\end{abstract}

device. Patients were interviewed 6 months post-surgery to determine the incidence and severity of chronic postsurgical pain.

Results: Mean \pm SD cumulative morphine (mg) consumption $(\mathrm{G} 1=49.4 \pm 24.8, \mathrm{G} 2=47.2 \pm 30.1$ and $\mathrm{G} 3=56.1 \pm$ 38.2 ) at $48 \mathrm{~h}$ and pain scores at $12,24,36$ and $48 \mathrm{~h}$ postsurgery were not significantly different among the groups [G1 $(n=38), \mathrm{G} 2(n=38)$ and G3 $(n=38)]$. Side effect profiles were similar across groups. Six months after surgery, the number of patients who reported chronic post-surgical pain $(\mathrm{G} 1=10, \mathrm{G} 2=12$ and $\mathrm{G} 3=9)$ and the severity of the pain $(\mathrm{G} 1=4.2 \pm 2.9, \mathrm{G} 2=4.1 \pm 2.2$ and $\mathrm{G} 3=4.9 \pm 2.2) \mathrm{did}$ not differ significantly among the groups $(P>0.05)$.

Conclusions: A single $600 \mathrm{mg}$ dose of gabapentin given pre-operatively or post-operatively does not reduce morphine consumption or pain scores in hospital or at 6 months after hip arthroplasty within the context of spinal anesthesia and a robust multimodal analgesia regimen.
$\mathrm{T}$ OTAL hip arthroplasty (THA) is associated with significant pain and decreased mobility in the immediate post-operative period. Moderate to severe post-operative pain is a frequent occurrence after many surgeries. ${ }^{1,2}$ Pain of this magnitude has been shown to interfere with post-operative rehabilitation, discharge from hospital, and to lead to the development of chronic pain in 3-35\% of hip arthroplasty patients. ${ }^{3}$ The addition of gabapentin, a non-opioid medication, is effective in reducing post-operative pain, opioid consumption and accelerating functional recovery in other types of surgery. ${ }^{4-6}$
Gabapentin, a structural analogue of $\gamma$-amino butyric acid, has been used as an anticonvulsant and antinociceptive drug. Its main binding site is the $\alpha-2-\delta$ subunit of voltage-dependent calcium channels. ${ }^{7}$ The side effects of gabapentin tend to be mild, with somnolence (20\%), dizziness $(18 \%)$, ataxia $(13 \%)$ and fatigue $(11 \%)$ being the most common. ${ }^{8}$ Over the past 8 years, many trials have examined the efficacy of gabapentin for the treatment of acute post-surgical pain. The surgical populations studied include abdominal or pelvic surgery, ${ }^{4,9-15}$ musculoskeletal surgery, ${ }^{5,16-22}$ head and neck surgery, ${ }^{23-25}$ breast surgery, ${ }^{26-29}$ varicocele 
surgery, ${ }^{30}$ thoracic surgery ${ }^{31}$ and recently cardiac surgery. $^{32}$ Of these randomized-controlled trials, most consisted of a single dose of gabapentin given before surgery. Only four of the above trials failed to demonstrate a decrease in pain scores or an opioid-sparing effect in the early post-surgical period. ${ }^{10,16,17,20}$

In the clinical setting, post-surgical pain is influenced by at least two factors: the inflammatory response, which is the consequence of trauma to peripheral tissues (i.e. surgical incision, dissection, burns), and intra-operative nerve damage arising from nerve transection, crushing or other nerve injury. ${ }^{33-35}$ Both factors result in long-term changes in the sensitivity of the central nervous system that amplify the peripheral signal either by excitatory or by disinhibitory mechanisms. It is now accepted that while general anesthesia may attenuate transmission of afferent injury barrage from the periphery to the spinal cord and brain, it does not block it. ${ }^{36}$ Moreover, systemic opioids may not provide a sufficiently dense blockade of spinal nociceptive neurons to prevent central sensitization. ${ }^{37}$ The processes leading to sensitization of dorsal horn neurons are largely unaffected by general anesthesia or routine doses of opioids. Gabapentin has been extensively studied in general anesthesia paradigms; however, few studies have examined its possible preemptive effect when regional anesthesia is used as the primary surgical modality. ${ }^{16,38}$

Preventive analgesia has evolved from preemptive analgesia by reducing the importance of blocking solely noxious pre-operative stimuli. ${ }^{34,39,40}$ The emphasis is on preventing or obtunding the peripheral nociceptive barrage and central sensitization that arise throughout the entire peri-operative period and not simply on blocking pre-operative noxious afferent input. A preventive analgesic effect is demonstrated when post-operative pain and/or analgesic consumption is reduced relative to another intervention, as long as the effect is observed at a point in time that exceeds the clinical duration of action of the target agent. One approach to ascertaining the outer limit of the clinical duration of action of the target agent is to assess pain and analgesic consumption at time points $>5.5$ half-lives of the pharmacologic intervention. $^{41}$

In order to facilitate the translation of research into clinical practice, it is important that trials mirror clinical practice. Multimodal analgesia is becoming the standard of practice in most institu- tions. This practice involves the use of different classes of analgesic agents with different routes of administration to ${ }^{1}$ provide superior pain relief at rest and after movement, ${ }^{2}$ reduce opioid consumption and ${ }^{3}$ reduce analgesic-related adverse effects. $^{42,43}$ Although many clinical trials have demonstrated the effectiveness of multimodal analgesia, positive results may not translate into clinical practice. ${ }^{44,45}$ This trial was designed to evaluate the efficacy of gabapentin in the context of a multimodal regimen including pre-operative spinal anesthesia (bupivacaine), a COX-2 antagonist (celecoxib), acetaminophen and a steroid (dexamethasone). Although single-agent therapy may attenuate the central nociceptive processing, multimodal therapy is more effective, and may be associated with fewer side effects compared with the high-dose, single-agent therapy. ${ }^{46,47}$

More specifically, the novel aspects of this study were to determine whether (1) a $600 \mathrm{mg}$ dose of gabapentin, added to a robust multimodal analgesia regimen, further reduces pain and opioid use after THA under spinal anesthesia; (2) a $600 \mathrm{mg}$ dose of gabapentin is more effective before vs. after surgery (i.e. a preemptive effect); and (3) this intervention leads to any difference in the incidence and severity of chronic pain at 6 months (i.e. a preventive effect).

\section{Materials and methods}

\section{Patient sample and recruitment procedures}

The study was approved by the hospital's Research Ethics Board and all patients gave informed, written consent to participate. The CONSORT guidelines were followed (i.e. statement for improving the quality of reports of parallel-group randomized trials) with respect to the reporting of this randomized control trial. ${ }^{48}$ Patients between the ages of 18 and 75 with an ASA physical status score of I, II or III undergoing THA were eligible for this study. Patients were not eligible if they had a known allergy to any of the medications being used, a history of drug or alcohol abuse, a history of being on chronic pain medications (i.e. slow-release preparations of opioids), rheumatoid arthritis, a psychiatric disorder, a history of diabetes with impaired renal function, a body mass index (BMI) of $>45$ or patients unable or unwilling to use patient-controlled analgesia. (PCA).

Patients were recruited at their pre-operative assessment visit approximately 1-2 weeks in 
advance of their surgery. All subjects were screened, and the study protocol, the use of the PCA pump and the visual analogue pain scale (VAS), a $10 \mathrm{~cm}$ scale (with endpoints labeled 'no pain' and 'worst pain possible'), were explained.

\section{Drug preparation, dispensing and randomization} Gabapentin and placebo medications were encapsulated in identically colored gelatin capsules and packaged in identical individual blister packs by the Sunnybrook Health Sciences Centre Investigational Pharmacy in order to maintain double-blind conditions. The placebo pills contained a mixture of $50 \%$ cellulose and $50 \%$ lactose monohydrate. A computer-generated randomization schedule was used to assign patients at random in blocks of six to one of the three treatment groups. The schedule was created by the hospital investigational pharmacy, which was otherwise not involved in the clinical care of the patients or in the conduct of the trial. The randomization schedule was kept in the pharmacy and none of the investigators had access to it. The pharmacy dispensed the capsules according to the randomization schedule when the investigators informed them that a patient had been recruited into the trial.

\section{Pre-, intra- and post-operative procedures}

On the day of surgery, all patients received acetaminophen $1000 \mathrm{mg}$ per os (p.o.), celecoxib $400 \mathrm{mg}$ p.o. and dexamethasone $8 \mathrm{mg}$ intravenously (i.v.), 1-2 $\mathrm{h}$ pre-operatively. Patients were randomly assigned to one of three treatment groups (G1: Placebo/Placebo; G2: GBP/Placebo; and G3: Placebo/GBP). Group 2 received gabapentin $600 \mathrm{mg}$ p.o. $2 \mathrm{~h}$ before surgery; the other groups received an identical-looking placebo capsule.

All patients were prepared for surgery in a specialized block area. Using an $18 \mathrm{~g}$ i.v. cannula, the anesthetist started an i.v. infusion of Lactated Ringer's solution. Blood pressure, ECG and oximetry monitors were applied. Midazolam 1-3 mg i.v. was administered to achieve anxiolysis. Spinal anesthesia was performed in the lateral decubitus or sitting position. After subcutaneous infiltration with lidocaine $1 \%$, and using a midline approach, a 25-G Whitacre needle (Beckton Dickinson and Company, Franklin Lakes, NJ, USA) was inserted at the L3-4, L4-5 or L5-S1 interspace, with the aperture directed to the side of surgery. When free flow of CSF was obtained, $15 \mathrm{mg}$ of $0.5 \%$ hypobaric bupivacaine with $10 \mu \mathrm{g}$ of fentanyl was injected. In all groups, the total volume injected into the subarachnoid space was $3.2 \mathrm{ml}$, with aspiration at the end of injection to ensure that the entire drug was injected intrathecally. The patient was then placed in the lateral decubitus position with the side of surgery uppermost. Patients were then transferred to the operating room, where monitors were reapplied, supplemental oxygen was provided and sedation was administered by an i.v. propofol infusion $(25-100 \mathrm{mcg} / \mathrm{kg} / \mathrm{min}$ ) until the end of surgery. The attending anesthesiologist was not involved in the patients' evaluation post-operatively.

Upon arrival to the recovery room, group 3 received gabapentin $600 \mathrm{mg}$ p.o.; the other groups received an identical-looking placebo capsule. At the time of PCA hookup in the post-anesthetic care unit (PACU) $(0 \mathrm{~h})$ and every $4 \mathrm{~h}$ for the next $48 \mathrm{~h}$, patients were asked to record their pain intensity at rest and after movement using a $10 \mathrm{~cm}$ VAS. The PCA pump was set to deliver morphine at $1 \mathrm{mg}$ per demand with a 5-min lockout and no background infusion. All patients were instructed to maintain their VAS pain score $<4 / 10$. If the VAS pain score at rest was $5 \mathrm{~cm}$ or greater on two consecutive 4-hourly assessments, the dose of i.v. PCA morphine was increased to $1.5 \mathrm{mg}$ per demand. At each time point after pain was measured, patients were assessed for the incidence and severity of sedation, nausea, vomiting and pruritus. On post-operative day 1, movement-evoked pain was measured in a standardized manner by asking patients to rate their pain on a VAS after moving from a lying to a sitting position at the edge of the bed.

Patients were followed up by telephone 6 months after surgery. A maximum of three calls were made and a voice message was left on the third call. Patients were considered lost to followup if they could not be reached and did not return the call. Patients were administered three questionnaires: a follow-up Hip Arthroplasty Pain questionnaire, The Neuropathic Pain Scale ${ }^{49}$ and The Hospital Anxiety and Depression Scale. ${ }^{50}$ Pain intensity was measured using a numeric rating scale (NRS). The NRS consists of a series of numbers ranging from 0 to 10 , with endpoints representing the most extreme pain experiences $(0=$ no pain and $10=$ worst possible pain). The NRS has been shown to have good reliability and validity and is sensitive to change following a pharmacological intervention. ${ }^{51}$ 
Sample size estimate

In order to determine the number of patients to recruit, data were collected from retrospective chart reviews because we were unable to find a published study examining the effect of gabapentin on pain or morphine consumption in the hip arthroplasty population. After identifying a small subset of charts that resembled the study population (i.e. used a similar anesthetic technique with and without gabapentin), we extracted cumulative PCA morphine consumption. The patients who were given gabapentin before surgery $(n=10)$ used $19.06 \pm 19.9 \mathrm{mg}$ [mean \pm standard deviation (SD)] in the first $24 \mathrm{~h}$ after surgery. The postoperative gabapentin group $(n=6)$ (i.e. administered on arrival in the PACU but not before) used $34.8 \pm 13.1 \mathrm{mg}$ (mean \pm SD) in the first $24 \mathrm{~h}$ after surgery. This study was powered to detect a difference between patients who received pre-operative gabapentin vs. post-operative gabapentin. Using the means and standard deviations from our chart review, we determined that 30 subjects per arm $(n=90)$ would provide $95 \%$ power at an $\alpha$ set at 0.05 to detect a difference of $15.8 \mathrm{mg}$ of morphine consumption between the patients who received gabapentin pre-operatively vs. in the PACU.

\section{Statistical analysis}

Data were analyzed using Statistical Analysis Software (SAS for Windows, version 9.1, SAS Institute Inc., Cary, NC). Demographic data and clinical variables were compared using the non-parametric Kruskal-Wallis test for the continuous and Fisher's exact test for the categorical variables.

Morphine consumption. Morphine consumption, measured at four time points $(12,24,36$ and $48 \mathrm{~h}$ post-surgery), was analyzed by a mixed model (PROC MIXED) ANOVA. The model used an autoregressive correlation structure within subjects that decreases with increasing time lag between measures, and an inter-subject random effect of differences between subjects. Group, time and interaction effects were tested with the model. The presence of a significant interaction effect would suggest a difference in the rates of consumption among the three groups.

VAS pain scores. VAS pain scores at rest and after reported movement, measured at 12-, 24-, 36- and 48-h time points, were analyzed by a mixed model
ANOVA as above. The empirical distribution of the scores was investigated visually using histograms, and the deviation of the normality assumption of the models was not considered significant. Postoperative day $^{52} 1$ VAS pain scores while the patient moved from lying to sitting were compared between groups using non-parametric KruskalWallis test.

Adverse effects. Sedation, nausea, vomiting, pruritus and dizziness were assessed across the 48-h period. Scores were calculated as the proportion of the time points (where a non-missing value was measured) at which the patient experienced the specific adverse effect. Patients were then classified based on the number of times the specific adverse effect was present: $0 \%$, up to $30 \%$ and larger than $30 \%$. The categorizations were compared among the three treatment groups using Fisher's exact test.

\section{Six-month follow-up}

The 6-month pain data were analyzed using the Statistical Package for the Social Sciences (version 16.0 for Windows, SPSS Inc., Chicago, IL). Ordinal variables were compared using the non-parametric Kruskal-Wallis test for independent samples. Categorical variables were analyzed using Fisher's exact test.

\section{Results}

\section{Recruitment and retention of patients}

Figure 1 shows the flow chart outlining the recruitment and retention of study patients.

Overall, 439 patients were screened for recruitment into the trial between May 2006 and April 2008. Of these, 121 did not meet the inclusion criteria (34 were older than 75 years of age, 29 had diabetes and/or an elevated creatinine, 16 declared an allergy to one of the study medications, 12 had a history of being on chronic pain medications, 11 presented with a psychiatric disorder, nine had a $\mathrm{BMI}>45$, five were not proficient in English and five had rheumatoid arthritis). Of the 318 patients who were eligible to participate, 126 patients were randomized to one of the three study groups. One hundred and fourteen patients completed the inhospital protocol. The reasons for not completing the in-hospital protocol were cancellation of surgery after taking the pre-operative medications $(n=4)$, patients who requested withdrawal from the study $(n=2)$, patients who received general anesthesia 
$(n=2)$, failure of the spinal anesthetic $(n=1)$, surgeon withdrawal of patient $(n=1)$ and one patient who had a more extensive surgical procedure performed ( $n=1$ ) (see Fig. 1).

Six months after surgery, 82 (71.9\%; 51 male, 31 female) patients were followed up.

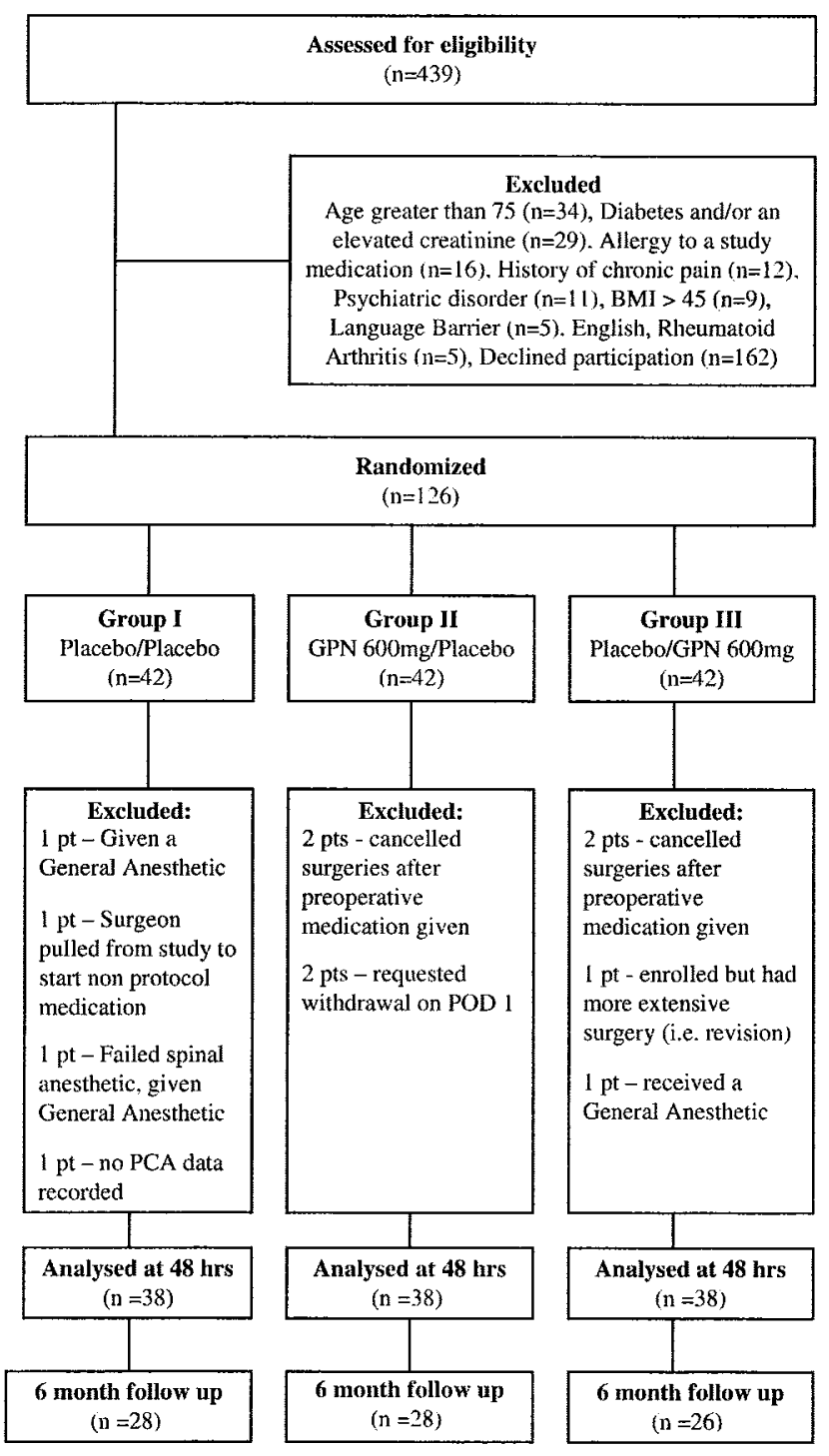

Fig. 1. Flow diagram of patient distribution.
Between the in-hospital intervention and 6month follow-up, 20 patients were lost to followup (unable to be contacted) and 12 refused to be interviewed. Of the 82 patients who were followed up, 28, 28 and 26 patients were in groups 1, 2 and 3, respectively.

\section{Demographic and clinical variables}

Table 1 shows the demographic and clinical variables describing the sample of 117 patients. The groups were comparable with respect to age, gender, BMI, ASA status and duration of surgery.

\section{In-hospital intervention}

Overall, significant differences among the three groups (G1 = Placebo, G2 = Preemptive GPN and $\mathrm{G} 3=$ Post-operative GPN) were not found ( $P=$ 0.53) in morphine consumption over the first 48 post-operative hours (Fig. 2). The group $x$ time interaction effect (measuring possible differences in the rates of consumption) was not significant $(P=$ $0.09)$. Likewise, pain scores did not differ significantly at rest $(P=0.49)$ or with movement $(P=$ 0.91 ) over the first $48 \mathrm{~h}$ (Fig. 3 ). The group $x$ time interaction was not significant for rest or movement pain scores ( $P=0.94$ and 0.11 , respectively). On post-operative day 1 , there was no difference in pain scores upon moving from the lying to the sitting position at the edge of the bed (G1 $=39.4 \pm$ $25.8, \mathrm{G} 2=40.3 \pm 22.0$ and G3 $=38.7 \pm 24.5$ ) (mean $\pm \mathrm{SD})(P=0.89)$. Finally, the three groups did not differ significantly with respect to sedation $(P=$ $0.51)$, nausea $(P=0.95)$, vomiting $(P=0.2)$, pruritus $(P=0.79)$ or dizziness $(P=0.84)$ (Table 2$)$.

\section{Six-month chronic pain follow-up}

Six months following THA surgery, neither the incidence of chronic post-surgical pain nor anxiety or depression scores differed significantly among the groups (all $P>0.05$ ). Of the 82 patients who

Table 1

\begin{tabular}{llll}
\hline \multicolumn{2}{l}{ Demographic characteristics and duration of surgery. } & & \\
\hline Variable & (G1) Placebo/Placebo $(n=39)$ & (G2) GPN 600/Placebo $(n=40)$ & (G3) Placebo/GPN 600 $(n=38)$ \\
\hline Age (year) & $61.3 \pm 10.7$ & $58.9 \pm 9.4$ & $60.4 \pm 8.1$ \\
Gender (M/F) & $21 / 18$ & $27 / 11$ & $22 / 16$ \\
Body mass index (BMI) & $29.2 \pm 5.3$ & $29.2 \pm 5.4$ & $29.0 \pm 6.3$ \\
ASA (I/II/II) & $5 / 28 / 6$ & $6 / 28 / 6$ & $7 / 26 / 5$ \\
Duration of surgery (min) & $73.8 \pm 22.7$ & $76.0 \pm 19.8$ & $70.9 \pm 15.0$ \\
\hline
\end{tabular}

Data are mean \pm SD. No significant differences were observed among groups. 


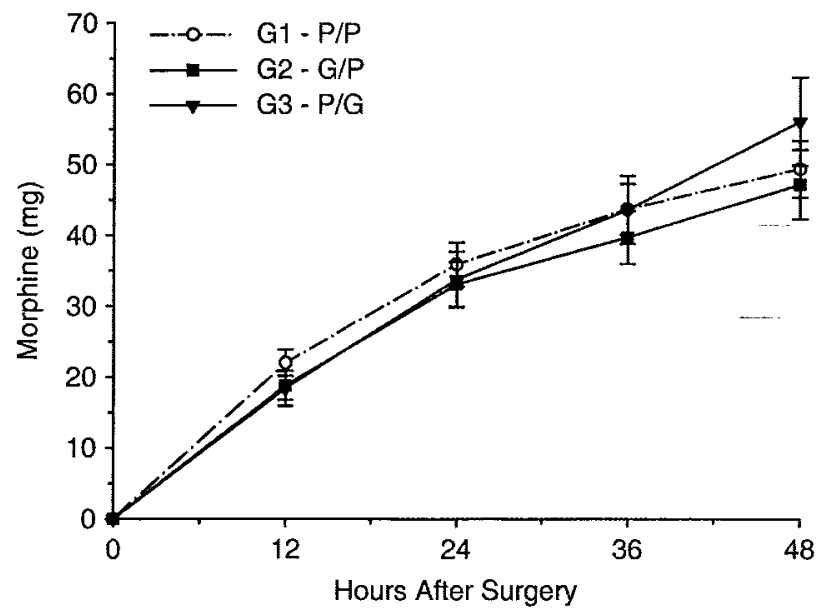

Fig.2. Cumulative morphine consumption after total hip arthroplasty. Overall, no significant differences were found among the three groups (G1 = Placebo/Placebo, G2 = Preemptive GPN/Placebo and G3 = Placebo/Post-operative GPN) in morphine consumption over the first 48 post-operative hours $(\mathrm{P}=0.53)$.

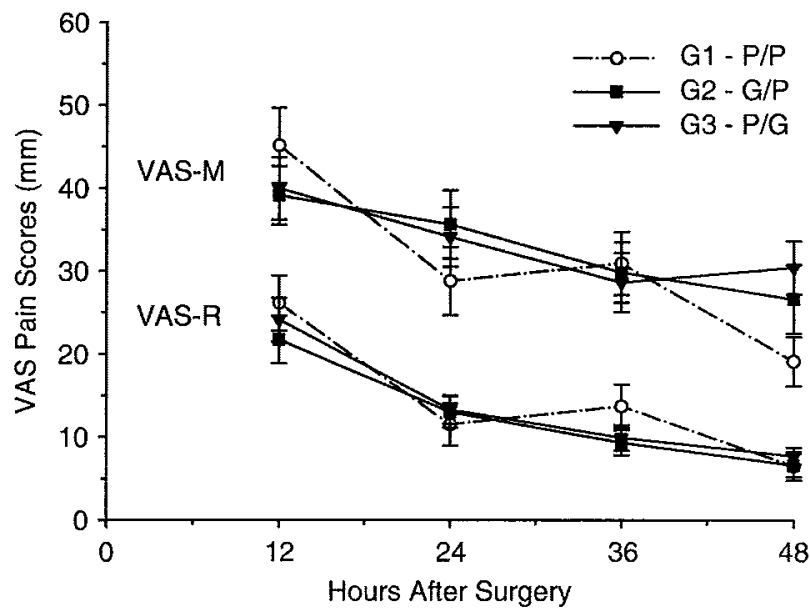

Fig.3. Pain scores at rest and with movement after total hip arthroplasty $(G 1=$ Placebo/Placebo, G2 = Preemptive GPN/Placebo and G3 = Placebo/Post-operative GPN). Pain scores did not differ at rest $(\mathrm{P}=0.49)$ or with movement $(\mathrm{P}=0.91)$ over the first $48 h$.

were interviewed at 6 months, $31(37.8 \%)$ patients reported chronic pain related to their hip arthroplasty (i.e. $27 \%$ of the entire study cohort). The characteristics/severity of the pain described by the 31 patients who reported pain $(\mathrm{G} 1=10, \mathrm{G} 2=12$ and $G 3=9$ ) are shown in Table 3 . The average pain scores reported at 6 months were $<4 / 10$ and appeared to have minimal impact on daily functioning. Pain scores at 'the worst' were in the moderate range $(\mathrm{G} 1=4.2 \pm 2.9, \mathrm{G} 2=4.1 \pm 2.2$ and $\mathrm{G} 3=4.9 \pm 2.2)(P=0.61)$.
Table 2

\begin{tabular}{|c|c|c|c|}
\hline $\begin{array}{l}\text { Percent of time } \\
\text { patient experienced }\end{array}$ & $\begin{array}{l}(\mathrm{G} 1) \\
\text { Placebo/ } \\
\text { Placebo } \\
(n=38)\end{array}$ & $\begin{array}{l}(\mathrm{G} 2) \\
\text { GPN 600/ } \\
\text { Placebo } \\
(n=38)\end{array}$ & $\begin{array}{l}\text { (G3) } \\
\text { Placebo/ } \\
\text { GPN 600 } \\
(n=38)^{-}\end{array}$ \\
\hline \multicolumn{4}{|l|}{ Sedation } \\
\hline $0 \%$ sedation & 31 & 31 & 27 \\
\hline$<30 \%$ sedation & 7 & 6 & 10 \\
\hline$>30 \%$ sedation & 0 & 1 & 1 \\
\hline \multicolumn{4}{|l|}{ Nausea } \\
\hline $\begin{array}{l}0 \% \text { nausea } \\
<30 \% \text { nausea }\end{array}$ & $\begin{array}{l}24 \\
13\end{array}$ & $\begin{array}{l}26 \\
11\end{array}$ & $\begin{array}{l}26 \\
11\end{array}$ \\
\hline$>30 \%$ nausea & 1 & 1 & 1 \\
\hline \multicolumn{4}{|l|}{ Pruritus } \\
\hline $0 \%$ pruritus & 28 & 31 & 27 \\
\hline$<30 \%$ pruritus & 8 & 6 & 9 \\
\hline \multicolumn{4}{|l|}{ Dizziness } \\
\hline $0 \%$ dizziness & 30 & 31 & 27 \\
\hline$<30 \%$ dizziness & 8 & 7 & 10 \\
\hline$>30 \%$ dizziness & 0 & 1 & 1 \\
\hline \multicolumn{4}{|l|}{ Vomiting } \\
\hline $\begin{array}{l}0 \% \text { vomiting } \\
<30 \% \text { vomiting }\end{array}$ & 7 & 7 & $\begin{array}{r}30 \\
2\end{array}$ \\
\hline
\end{tabular}

*Indicates significant difference $P<0.05$.

\section{Discussion}

Gabapentin has been efficacious in reducing opioid consumption after many types of surgery. 4,5,9,13-15,18 Meta-analyses have demonstrated that this anticonvulsant leads to a reduction in post-operative opioid use and a reduction in postoperative pain scores. ${ }^{53-55}$ The results of the present study demonstrate that a $600 \mathrm{mg}$ dose of gabapentin, whether administered pre-operatively or post-operatively, in the context of a robust multimodal analgesia regimen with spinal anesthesia, does not reduce post-operative opioid consumption or pain scores (Figs 2 and 3). Given the recent increase in the use of gabapentin within the perioperative setting, this novel work examines the potential added benefit of a single preemptive dose to an already clinically robust pain regimen. When compared with the current gabapentin literature, this trial has a larger sample size than most studies published thus far. Therefore, our results question the addition of a single dose of gabapentin to an already satisfactory clinical regimen. However, gabapentin continued into the post-operative period has been found to be beneficial for movement-evoked pain in other patient populations ${ }^{4,5}$ and may also be beneficial with respect to postarthroplasty rehabilitation. The potential benefit of the gabapentinoids on improving inpatient rehabi- 
Six-month pain profile (patients with chronic pain only).

\begin{tabular}{|c|c|c|c|}
\hline$\cdots$ & $\begin{array}{l}\text { (G1) Placebo/Placebo } \\
(n=10 \text { of } 28 \text { patients } \\
\text { reported chronic } \\
\text { post-surgical pain) }\end{array}$ & $\begin{array}{l}\text { (G2) GPN } 600 / \text { Placebo } \\
\text { ( } n=12 \text { of } 28 \text { patients } \\
\text { reported chronic } \\
\text { post-surgical pain) }\end{array}$ & $\begin{array}{l}\text { (G3) Placebo/GPN } 600 \\
(n=9 \text { of } 26 \text { patients } \\
\text { reported chronic } \\
\text { post-surgical pain) }\end{array}$ \\
\hline $\begin{array}{l}\text { Total hip arthroplasty follow-up pain questionnaire } \\
\text { How often do you have pain at your arthroplasty } \\
\text { site? }\end{array}$ & $\begin{array}{l}\text { Constant: } 2 \\
\text { Periodic: } 5 \\
\text { Brief: } 3\end{array}$ & $\begin{array}{l}\text { Constant: } 4 \\
\text { Periodic: } 5 \\
\text { Brief: } 3\end{array}$ & $\begin{array}{l}\text { Constant: } 1 \\
\text { Periodic: } 4 \\
\text { Brief: } 4\end{array}$ \\
\hline $\begin{array}{l}\text { Measurement of allodynia: number of patients who } \\
\text { reported that running their finger along their scar is } \\
\text { painful. }\end{array}$ & 2 & 1 & 0 \\
\hline $\begin{array}{l}\text { Measurement of hyperalgesia: number of patients } \\
\text { who reported that lifting their knee to } 90^{\circ} \text { hurt or felt } \\
\text { uncomfortable. }\end{array}$ & 3 & 3 & 4 \\
\hline $\begin{array}{l}\text { Usual intensity of your post hip arthroplasty site } \\
\text { pain }(0-10)\end{array}$ & $3.4 \pm 1.6$ & $3.1 \pm 1.9$ & $3.1 \pm 1.5$ \\
\hline $\begin{array}{l}\text { The worst intensity of your post hip arthroplasty site } \\
\text { pain }(0-10)\end{array}$ & $5.6 \pm 3.1$ & $4.6 \pm 1.9$ & $5.3 \pm 2.1$ \\
\hline $\begin{array}{l}\text { The extent to which your post hip arthroplasty site } \\
\text { pain interferes with your everyday activities }(0-10) \\
\text { Neuropathic pain scale items }\end{array}$ & $3.9 \pm 3.3$ & $3.6 \pm 3.6$ & $4.1 \pm 3.6$ \\
\hline Q.1 How intense is your pain & $3.6 \pm 1.9$ & $2.9 \pm 1.7$ & $3.9 \pm 2.6$ \\
\hline Q.2 How sharp your pain feels & $2.2 \pm 2.3$ & $2.1 \pm 2.7$ & $2.4 \pm 1.9$ \\
\hline Q.3 How hot your pain feels & $0.9 \pm 1.9$ & $0.2 \pm 0.4$ & $0.6 \pm 1.1$ \\
\hline Q.4 How dull your pain feels & $3.3 \pm 2.9$ & $2.0 \pm 2.5$ & $3.0 \pm 2.2$ \\
\hline Q.5 How cold your pain feels & $0.3 \pm 0.9$ & $1.0 \pm 2.0$ & $0.0 \pm 0.0$ \\
\hline $\begin{array}{l}\text { Q.6 How sensitive your skin is to light touch or } \\
\text { clothing }\end{array}$ & $1.6 \pm 2.8$ & $0.5 \pm 1.0$ & $0.3 \pm 1.0$ \\
\hline Q.7 How itchy your pain feels & $0.0 \pm 0.0$ & $0.8 \pm 1.6$ & $0.1 \pm 0.3$ \\
\hline Q.8 How unpleasant your pain feels & $3.7 \pm 2.6$ & $3.7 \pm 2.7$ & $3.1 \pm 3.2$ \\
\hline Q.10a How unpleasant is your deep pain. & $4.0 \pm 2.8$ & $2.9 \pm 2.4$ & $3.9 \pm 2.5$ \\
\hline $\begin{array}{l}\text { Q.10b How unpleasant is your superticial pain } \\
\text { Hospital anxiety and depression scores }\end{array}$ & $1.4 \pm 1.4$ & $0.9 \pm 1.0$ & $0.3 \pm 1.0$ \\
\hline Anxiety score & $5.8 \pm 3.0$ & $5.1 \pm 2.6$ & $3.0 \pm 2.3$ \\
\hline Depression score & $4.0 \pm 3.0$ & $3.1 \pm 2.9$ & $5.1 \pm 5.4$ \\
\hline
\end{tabular}

Data are mean \pm SD. No significant differences were observed among groups. PACU, post-anesthetic care unit.

litation throughout the peri-operative stay is currently under investigation and a recent publication has shown promising results with improvement in active assisted knee flexion after total knee arthroplasty. ${ }^{6}$ Recent studies looking at gabapentin in association with regional anesthesia techniques have yielded mixed results. A recent study by Turan et al. ${ }^{22}$ showed that gabapentin (1200 mg day) as an adjunct to epidural analgesia decreased pain and analgesic consumption in patients who had undergone lower extremity surgical procedures. In a second study by the same group, ${ }^{38}$ the same dose of gabapentin administered pre-operatively decreased tourniquet-related pain and improved the quality of anesthesia during hand surgery under intravenous regional anesthesia. In contrast, Adam et al. ${ }^{16}$ found that a single preoperative dose of $800 \mathrm{mg}$ of gabapentin did not augment post-operative analgesia in patients given interscalene brachial plexus blocks for arthroscopic shoulder surgery. Similarly, Brogly et al. ${ }^{56}$ recently demonstrated that patients undergoing a thyroidectomy and receiving a single preemptive dose of $1200 \mathrm{mg}$ of gabapentin within the context of cervical plexus blocks did not experience a reduction in acute pain or opioid consumption. However, a single $1200 \mathrm{mg}$ dose of gabapentin did prevent delayed neuropathic pain at six months compared with the patients who received placebo. ${ }^{56} \mathrm{It}$ is clear that gabapentin in conjunction with regional anesthesia regimens, needs further investigation with respect to the timing and the duration of administration post-operatively.

The results of the present study indicate that the rationale for using a single pre-operative dose of gabapentin in the context of regional anesthesia should be questioned. Unless gabapentin significantly modifies central sensitization in the long term, the addition of a single preoperative dose in conjunction with regional blocks seems to be 
somewhat redundant. Given the ability of local anesthetics to completely block pain and decrease morphine consumption in the acute post-surgical time period, the addition of a single pre-operative dose will likely not further reduce pain or opioid consumption as demonstrated by our results and others. ${ }^{16,56}$ However, starting gabapentin preoperatively and continuing this medication into the post-operative time period could lead to an opioid-sparing effect and may reduce pain with functional recovery and rehabilitation., ${ }^{4,6}$ Gabapentin has been investigated as an adjunct to rehabilitation due to its efficacy in reducing movement-evoked pain. ${ }^{4-6,13,15,23,26,28}$

Pandey et al. ${ }^{18}$ randomized patients undergoing lumbar discectomy to receive a one-time dose of either placebo or gabapentin 300,600, 900 or $1200 \mathrm{mg}$ pre-operatively. The optimal dose was $600 \mathrm{mg}$; at higher doses ( 900 and $1200 \mathrm{mg}$ ), patients exhibited more side effects with no additional reduction in pain. At our institution, patients who received $>600 \mathrm{mg}$ of gabapentin before surgery as part of daily clinical practice demonstrated an increased incidence of sedation. Using a design similar to that of the present study, and using the same patient population, Mathiesen et al. ${ }^{57}$ randomized 120 patients to either (A) placebo, (B) pregabalin $300 \mathrm{mg}$ or (C) pregabalin $300 \mathrm{mg}$ and dexamethasone $8 \mathrm{mg}$ before THA. All patients also received acetaminophen $1 \mathrm{~g}$ and a standardized spinal anesthetic before surgery. After $24 \mathrm{~h}$, morphine consumption was significantly reduced in groups $\mathrm{B}$ and $\mathrm{C}$ compared with group $\mathrm{A}$. There are differences between the present study and that of Mathiesen and colleagues. First, the bioequivalent dose of $300 \mathrm{mg}$ pregabalin is approximately $1800 \mathrm{mg}$ of gabapentin $(6: 1)$, which would be three times the dose used in our trial (which also demonstrated increased sedation). Second, Mathiesen and colleagues did not use a COX-2 antagonist as part of their pain regimen. It is clear that more work needs to be carried out with regard to the optimal dosing of gabapentin in various surgical populations and the determination of the efficacy at treating post-operative pain beyond the immediate 24 or $48 \mathrm{~h}$ of surgery.

Most trials thus far have compared gabapentin with placebo. Gilron et al. $^{4}$ and Turan et al. ${ }^{15}$ published studies in which they administered Gabapentin and Cox II inhibitors, and compared with each agent in isolation. Both studies demonstrated a superior opioid-sparing and pain-reducing effect in patients who received the multimodal interven- tion. Our multimodal regimen involved spinal anesthesia (bupivacaine), a COX-2 antagonist (celecoxib), acetaminophen and a steroid (dexamethasone). Using the above multimodal regimen, we likely established an effective level of preemptive analgesia before the surgical injury, and then continued the effective analgesic level well into the post-injury period to prevent central sensitization during the immediate post-operative time period. The pain scores were excellent throughout our trial (Fig. 3). Regardless of the intervention (gabapentin administration before or after surgery or placebo), patients reported pain scores in the mild range $(<4 / 10)$ at rest, with movement and while moving from lying to sitting on POD1. It is clear that the single dose of gabapentin had no effect on an already robust peri-operative pain regimen.

Six months following THA surgery, the incidences of chronic post-surgical pain, anxiety and depression scores were similar across groups. Of the 82 patients who were reached via a telephone interview, 31 patients (37.8\%) reported chronic pain related to their hip arthroplasty. It has been suggested that the severity of acute pain may be related to the development of chronic pain. ${ }^{1,58,59}$ Other mechanisms underlying the transition to chronicity may involve ectopic neural activity, ${ }^{60}$ psychological factors ${ }^{61}$ and genomics. ${ }^{62}$ Forty percent $(40 \%)$ of the patients in the present study reported post-surgical pain at 6 months notwithstanding the mild acute pain intensity experienced in the days after surgery. At the 6-month interview, the usual intensity of the pain was $<4 / 10$ across all groups and the pain did not interfere significantly with their daily activities. It is important to note that this study was powered for acute pain outcomes; even though we were able to contact $71 \%$ of patients post-operatively, the possibility remains that this study may be underpowered to detect group differences with respect to the intensity of chronic post-surgical pain. The incidence of chronic post-surgical pain at 6 months $(37.8 \%)$ may be an over-estimate of the true incidence because it is possible that mainly patients with chronic pain agreed to be followed up. Using the entire cohort as the denominator yielded a lower estimate $(27 \%)$ of the incidence, which remains higher than expected.

This study has several limitations. First, the optimal dose of preemptive gabapentin has not been elucidated in hip arthroplasty patients. It is unlikely that giving even higher doses of this anticonvulsant in the context of regional anesthesia would change the observed outcome in the context 
of regional anesthesia techniques (spinal blockade, peripheral blocks, etc.) because the half-life of a single dose of gabapentin (i.e. 6-8 h) often does not outlast the effective times of the regional anesthetic. The present results are specific to our multimodal analgesic design and cannot be generalized to the same surgery and other surgeries performed under general anesthesia. Second, even though the incidence of chronic pain seen in this study is higher than reported elsewhere in the literature, ${ }^{3}$ the severity and impact on patient functioning appears to be minor (Table 3). Another limitation is that we did not assess the incidence or the intensity of pain before surgery. Given that the majority of patients undergoing THA have significant levels of pain and disability before surgery, ${ }^{63}$ it is quite possible that the $37.8 \%$ (who reported mild pain 6 months after surgery) represents an improvement relative to their pre-operative pain and functioning. Future studies examining the course of pain over time should collect baseline pre-operative data.

In conclusion, a single $600 \mathrm{mg}$ dose of gabapentin, whether given pre-operatively or post-operatively, did not reduce morphine consumption or pain scores in hospital or at 6 months post hip arthroplasty. Gabapentin administration, in conjunction with regional anesthesia and multimodal regimens, requires further investigation with respect to the timing and the duration of administration post-operatively.

\section{Acknowledgements}

This study was made possible through a grant by the Physicians' Services Incorporated. Many thanks are due to our study co-ordinator Beth Goudie RN and the Holland Orthopedic and Arthritic Centre's Nursing staff, Pharmacy and Physiotherapy Departments for all of their hard work and support. We would also like to thank Eileen Halket RN, Aubrey Chiu and the Acute Pain Research team at the Toronto General Hospital for their many hours of hard work. Joel Katz is supported by a Canada Research Chair in Health Psychology at York University. There are no conflicts of interest to declare with regard to this work.

\section{References}

1. Katz J, Jackson M, Kavanagh BP, Sandler AN. Acute pain after thoracic surgery predicts long-term post-thoracotomy pain. Clin J Pain 1996; 12: 50-5.

2. Perkins FM, Kehlet $H$. Chronic pain as an outcome of surgery. A review of predictive factors. Anesthesiology 2000; 93: 1123-33.

3. Goldstein DH, Ellis J, Brown R, Wilson R, Penning J, Chisom K, VanDenKerkhof E. Recommendations for im- proved acute pain services: Canadian collaborative acute pain initiative. Pain Res Manag 2004; 9: 123-30.

4. Gilron I, Orr E, Tu D, O'Neill JP, Zamora JE, Bell AC. A placebo-controlled randomized clinical trial of perioperative administration of gabapentin, rofecoxib and their combination for spontaneous and movement-evoked pain after abdominal hysterectomy. Pain 2005; 113: 191-200.

5. Menigaux C, Adam F, Guignard B, Sessler DI, Chauvin M. Preoperative gabapentin decreases anxiety and improves early functional recovery from knee surgery. Anesth Analg 2005; 100: 1394-9.

6. Clarke H, Pereira S, Kennedy D, Katz J, Gollish J, Kay J. Gabapentin decreases morphine consumption and improves functional recovery following total knee arthroplasty. Pain Res Manag 2009; in press.

7. Cheng JK, Chiou LC. Mechanisms of the antinociceptive action of gabapentin. J Pharmacol Sci 2006; 100: 471-86.

8. Rose MA, Kam PC. Gabapentin: pharmacology and its use in pain management. Anaesthesia 2002; 57: 451-62.

9. Dierking G, Duedahl TH, Rasmussen ML, Fomsgaard JS, Moiniche S, Romsing J, Dahl JB. Effects of gabapentin on postoperative morphine consumption and pain after abdominal hysterectomy: a randomized, double-blind trial. Acta Anaesthesiol Scand 2004; 48: 322-7.

10. Fassoulaki A, Stamatakis E, Petropoulos G, Siafaka I, Hassiakos D, Sarantopoulos C. Gabapentin attenuates late but not acute pain after abdominal hysterectomy. Eur J Anaesthesiol 2006; 23: 136-41.

11. Pandey CK, Priye S, Singh S, Singh U, Singh RB, Singh PK. Preemptive use of gabapentin significantly decreases postoperative pain and rescue analgesic requirements in laparoscopic cholecystectomy. Can J Anaesth 2004; 51: 358-63.

12. Pandey CK, Singhal V, Kumar M, Lakra A, Ranjan R, Pal R, Raza M, Singh U, Singh PK. Gabapentin provides effective postoperative analgesia whether administered pre-emptively or post-incision. Can J Anaesth 2005; 52: 827-31.

13. Rorarius MG, Mennander S, Suominen P, Rintala S, Puura A, Pirhonen R, Salmelin R, Haanpaa M, Kujansuu E, YliHankala A. Gabapentin for the prevention of postoperative pain after vaginal hysterectomy. Pain 2004; 110: 175-81.

14. Turan A, Karamanlioglu B, Memis D, Usar P, Pamukcu Z, Ture $M$. The analgesic effects of gabapentin after total abdominal hysterectomy. Anesth Analg 2004; 98: 1370-3.

15. Turan A, White PF, Karamanlioglu B, Memis D, Tasdogan M, Pamukcu Z, Yavuz E. Gabapentin: an alternative to the cyclooxygenase-2 inhibitors for perioperative pain management. Anesth Analg 2006; 102: 175-81.

16. Adam F, Menigaux C, Sessler DI, Chauvin M. A single preoperative dose of gabapentin ( 800 milligrams) does not augment postoperative analgesia in patients given interscalene brachial plexus blocks for arthroscopic shoulder surgery. Anesth Analg 2006; 103: 1278-82.

17. Leung JM, Sands LP, Rico M, Petersen KL, Rowbotham MC, Dahl JB, Ames C, Chou D, Weinstein P. Pilot clinical trial of gabapentin to decrease postoperative delirium in older patients. Neurology 2006; 67: 1251-3.

18. Pandey CK, Navkar DV, Giri PJ, Raza M, Behari S, Singh RB, Singh U, Singh PK. Evaluation of the optimal preemptive dose of gabapentin for postoperative pain relief after lumbar diskectomy: a randomized, double-blind, placebocontrolled study. J Neurosurg Anesthesiol 2005; 17: 65-8.

19. Pandey CK, Sahay S, Gupta D, Ambesh SP, Singh RB, Raza M, Singh U, Singh PK. Preemptive gabapentin decreases postoperative pain after lumbar discoidectomy. Can J Anaesth 2004; 51: 986-9. 
20. Radhakrishnan M, Bithal PK, Chaturvedi A. Effect of preemptive gabapentin on postoperative pain relief and morphine consumption following lumbar laminectomy and discectomy: a randomized, double-blinded, placebocontrolled study. J Neurosurg Anesthesiol 2005; 17: 125-8.

21. Turan A, Karamanlioglu B, Memis D, Hamamcioglu MK Tukenmez B, Pamukcu Z, Kurt I. Analgesic effects of gabapentin after spinal surgery. Anesthesiology 2004; 100: 935-8.

22. Turan A, Kaya G, Karamanlioglu B, Pamukcu Z, Apfel CC. Effect of oral gabapentin on postoperative epidural analgesia. Br J Anaesth 2006; 96: 242-6.

23. Al-Mujadi H, A-Refai AR, Katzarov MG, Dehrab NA, Batra YK, Al-Qattan AR. Preemptive gabapentin reduces postoperative pain and opioid demand following thyroid surgery. Can J Anaesth 2006; 53: 268-73.

24. Mikkelsen S, Hilsted KL, Andersen PJ, Hjortso NC, Enggaard TP, Jorgensen DG, Hansen M, Henriksen J, Dahl JB. The effect of gabapentin on post-operative pain following tonsillectomy in adults. Acta Anaesthesiol Scand 2006; 50: 809-15.

25. Turan A, Memis D, Karamanlioglu B, Yagiz R, Pamukcu Z, Yavuz, E. The analgesic effects of gabapentin in monitored anesthesia care for ear-nose-throat surgery. Anesth Analg 2004; 99: 375-8.

26. Dirks J, Fredensborg BB, Christensen D, Fomsgaard JS, Flyger H, Dahl JB. A randomized study of the effects of single-dose gabapentin versus placebo on postoperative pain and morphine consumption after mastectomy. Anesthesiology 2002; 97: 560-4.

27. Fassoulaki A, Patris K, Sarantopoulos C, Hogan Q. The analgesic effect of gabapentin and mexiletine after breast surgery for cancer. Anesth Analg 2002; 95: 985-91.

28. Fassoulaki A, Triga A, Melemeni A, Sarantopoulos C. Multimodal analgesia with gabapentin and local anesthetics prevents acute and chronic pain after breast surgery for cancer. Anesth Analg 2005; 101: 1427-32.

29. Parsa AA, Sprouse-Blum AS, Jackowe DJ, Lee M, Oyama J, Parsa FD. Combined preoperative use of Celecoxib and Gabapentin in the management of postoperative pain. Aesthetic Plast Surg 2009; 33: 98-103.

30. Koc S, Memis D, Sut N. The preoperative use of gabapentin, dexamethasone, and their combination in varicocele surgery: a randomized controlled trial. Anesth Analg 2007; 105: 1137-42.

31. Huot MP, Chouinard P, Girard F, Ruel M, Lafontaine ER, Ferraro P. Gabapentin does not reduce post-thoracotomy shoulder pain: a randomized, double-blind placebo-controlled study. Can J Anaesth 2008; 55: 337-43.

32. Parlow J, Milne B, Gilron I, Shore D, Orr E. Gabapentin pharmacokinetics and feasibilty. In Cardiac Surgery. Halifax: Canadian Anesthesiology Society Kingston, Queens University, 2008.

33. Kelly DJ, Ahmad M, Brull SJ. Preemptive analgesia I: physiological pathways and pharmacological modalities. Can J Anaesth 2001; 48: 1000-10.

34. Katz J, Clarke H. Preventive analgesia and beyond: current status, evidence, and future directions. In: Macintyre P., ed. Clinical pain management: acute pain. London: Hodder Arnold Ltd, 2008, pp154-98.

35. Kissin I. Preemptive analgesia. Anesthesiology 2000; 93: 1138-43.

36. Rundshagen I, Kochs E, Schulte am Esch J. Surgical stimulation increases median nerve somatosensory evoked responses during isoflurane-nitrous oxide anaesthesia. $\mathrm{Br} \mathrm{J}$ Anaesth 1995; 75: 598-602.
37. Abram SE, Yaksh TL. Morphine, but not inhalation anesthesia, blocks post-injury facilitation. The role of preemptive suppression of afferent transmission. Anesthesiology 1993; 78: 713-21.

38. Turan A, White PF, Karamanlioglu B, Pamukcu Z. Premedication with gabapentin: the effect on tourniquet pain and quality of intravenous regional anesthesia. Anesth Analg 2007; 104: 97-101.

39. Katz J, McCartney CJ. Current status of pre-emptive analgesia. Curr Opin Anaesthesiol 2002; 15: 435-41.

40. Kissin I. Preemptive analgesia: terminology and clinical relevance. Anesth Analg 1994; 79: 809-10.

41. McCartney CJ, Sinha A, Katz J. A qualitative systematic review of the role of $N$-methyl-D-aspartate receptor antagonists in preventive analgesia. Anesth Analg 2004; 98: 1385400.

42. Brown AK, Christo PJ, Wu CL. Strategies for postoperative pain management. Best Pract Res Clin Anaesthesiol 2004; 18: 703-17.

43. Joshi GP. Multimodal analgesia techniques and postoperative rehabilitation. Anesthesiol Clin North Am 2005; 23 : 185-202.

44. Hsieh M, Yealy DM. Are we ignoring the evidence? Acad Emerg Med 2005; 12: 461-2.

45. Marshall ML. Strategies for success: bringing evidencebased practice to the bedside. Clin Nurse Spec 2006; 20: $124-7$.

46. Gilron I, Bailey JM, Tu D, Holden RR, Weaver DF, Houlden RL. Morphine, gabapentin, or their combination for neuropathic pain. N Engl J Med 2005; 352: 1324-34.

47. Moiniche S, Hjortso NC, Hansen BL, DahI JB, Rosenberg J, Gebuhr P, Kehlet $\mathrm{H}$. The effect of balanced analgesia on early convalescence after major orthopaedic surgery. Acta Anaesthesiol Scand 1994; 38: 328-35.

48. Moher D, Schulz KF, Altman D. The CONSORT statement: revised recommendations for improving the quality of reports of parallel-group randomized trials. J Am Med Assoc 2001; 285: 1987-91.

49. Galer BS, Jensen MP. Development and preliminary validation of a pain measure specific to neuropathic pain: the neuropathic pain scale. Neurology 1997; 48: 332-8.

50. Bjelland I, Dahl AA, Haug TT, Neckelmann D. The validity of the hospital anxiety and depression scale. An updated literature review. J Psychosom Res 2002; 52: 69-77.

51. Katz J, Melzack R. Measurement of pain. Surg Clin North Am 1999; 79: 231-52

52. Podsiadlo D, Richardson S. The timed "Up \& Go": a test of basic functional mobility for frail elderly persons. J Am Geriatr Soc 1991; 39: 142-8.

53. Ho KY, Gan TJ, Habib AS. Gabapentin and postoperative pain-a systematic review of randomized controlled trials. Pain 2006; 126: 91-101.

54. Peng PW, Wijeysundera DN, Li CC. Use of gabapentin for perioperative pain control - a meta-analysis. Pain Res Manag 2007; 12: 85-92.

55. Seib RK, Paul JE. Preoperative gabapentin for postoperative analgesia: a meta-analysis. Can J Anaesth 2006; 53: 461-9.

56. Brogly N, Wattier JM, Andrieu G, Peres D, Robin E, Kipnis E, Arnalsteen L, Thielemans B, Carnaille B, Pattou F, Vallet B, Lebuffe G. Gabapentin attenuates late but not early postoperative pain after thyroidectomy with superficial cervical plexus block. Anesth Analg 2008; 107: 1720-5.

57. Mathiesen O, Jacobsen LS, Holm HE, Randall S, AdamiecMalmstroem L, Graungaard BK, Holst PE, Hilsted KL, Dahl JB. Pregabalin and dexamethasone for postoperative pain 
control: a randomized controlled study in hip arthroplasty. Br J Anaesth 2008; 101: 535-41.

58. Brander VA, Stulberg SD, Adams AD, Harden RN, Bruehl S, Stanos SP, Houle T. Predicting total knee replacement pain: a prospective, observational study. Clin Orthop Relat Res 2003; 416: 27-36.

59. Thomas T, Robinson C, Champion D, McKell M, Pell M. Prediction and assessment of the severity of post-operative pain and of satisfaction with management. Pain 1998; 75: 177-85.

60. Pitcher GM, Henry JL. Governing role of primary afferent drive in increased excitation of spinal nociceptive neurons in a model of sciatic neuropathy. Exp Neurol 2008; 214: 219-28.

61. Katz J, Gordon A, McCrae K, Halket E. Emotional numbing and pain intensity predict the development of pain disability up to one year after lateral thoracotomy. Eur J Pain 2009; in press.
62. Edwards RR. Genetic predictors of acute and chronic pain. Curr Rheumatol Rep 2006; 8: 411-7.

63. Cremeans-Smith JK, Boarts JM, Greene K, Delahanty DL. Patients' reasons for electing to undergo total knee arthroplasty impact post-operative pain severity and range of motion. J Behav Med 2009; 32: 223-33.

Address:

Hance Clarke

Department of Anesthesia and Pain Management

Toronto General Hospital

Acute Pain Research Unit

200 Elizabeth Street

Eaton North 3 EB 317

Toronto

ON M5G 2C4

USA

e-mail: hance.clarke@utoronto.ca 